\title{
Legal and illegal drug use among female sex workers in bar and club prostitution in Belgium: A quantitative and qualitative study
}

\author{
Karolien van Nunen ${ }^{1}$, Elke Leuridan ${ }^{2}$, Guido Van Hal ${ }^{1}$, Pierre Van Damme $^{2}$, \& \\ Tom Decorte ${ }^{3}$ \\ ${ }^{1}$ Department of Epidemiology and Social Sciences, Faculty of Medicine and Health Sciences, Research Group \\ Medical Sociology and Health Policy, University of Antwerp, Antwerp, Belgium, ${ }^{2}$ Faculty of Medicine and \\ Health Sciences, Vaccine \& Infectious Disease Institute, Centre for the Evaluation of Vaccination, University \\ of Antwerp, Antwerp, Belgium, and ${ }^{3}$ Department of Penal Law and Criminology, Faculty of Law, Institute for \\ Social Drug Research, Ghent University, Ghent, Belgium
}

Aims: This study describes the amounts and effects of drug use in bar and club sex work, and the use of healthcare for the drug-related needs of sex workers (SW).

Methods: A cross-sectional study was carried out in Belgium. In a quantitative component, 120 bar and club SW were interviewed face-to-face by means of a semi-structured questionnaire. In a qualitative component, $25 \mathrm{SW}$ were interviewed face-to-face and 5 focus group discussions with key actors professionally involved with the study's subject were conducted.

Findings: Many bar and club SW drink frequently alcohol and engage in heavy drinking. Illegal drugs such as cannabis, cocaine and benzodiazepines are also frequently used. The drug use often involves poly or combined drug use. More than one-third experienced a certain degree of dependence on a product and many experienced effects from drug use on their sex work. The study shows that SW have difficulties accessing drug-related healthcare. Conclusions: SW use often legal and illegal drugs. The prevalence and influence of drug use among bar and club SW illustrates the need for drug and sex work related healthcare. Distribution of more information about the risks of drug use, the possible negative effects, and the available drug-related healthcare is needed.

\section{INTRODUCTION}

Female sex workers (SW) are often exposed to workrelated health risks such as an increased vulnerability to sexually transmitted infections (STIs), violence, unwanted pregnancies and psychological problems (Day \& Ward, 1997; Mak, Van Renterghem, \& Cuvelier, 2004; Ward \& Day, 2006).

Many researchers suggest that drug use among SW is associated with behaviour that implies an increase in the health risks mentioned above (Gossop, Powis, Griffiths, \& Strang, 1995). The term 'drugs' refers not only to illegal substances, but also to alcohol and prescription drugs used for non-medical purposes. The term 'sex work' means 'performing sexual services in exchange for objects of value'.

The use of drugs, and in particular stimulants, is connected with certain risk behaviour: sexual excitement increases, inhibitions are reduced and precautions such as consistent and efficient condom use are neglected (Falcón, 2007). Moreover, it is also reported that SW under the influence are less selective in picking clients, because their negotiation skills are reduced or because their ability to safeguard their personal limits is decreased (Degraaf, Vanwesenbeeck, Vanzessen, Straver, \& Visser, 1995). It may also make the SW more vulnerable to violence and other kinds of abuse (Gossop, Powis, Griffiths, \& Strang, 1994). In addition, sharing drugs with clients increases vulnerability to violence, sexual or drug-related harm. Sharing drugs is also connected to prolonged and aggressive sexual contact (Shannon, Kerr, Bright, Gibson, \& Tyndall, 2008). 
Apart from the dysfunctional effects mentioned above, there are also functional effects that are linked to substance use. Drug use is often perceived as a means of coping with work-related stress. Drugs help to forget about negative job-related feelings and to combat loathing for the clients. They can make SW less aware of their work and reduce their emotional involvement (Brooke, Taylor, Gunn, \& Maden, 1998; Gossop et al., 1994; Kumar \& Sharma, 2008; Maxwell \& Maxwell, 2000; Young, Boyd, \& Hubbell, 2000). Moreover, drug use is said to make different aspects of sex work easier. People who are under the influence tend to be more relaxed and may therefore be able to make contacts more easily. In particular, alcohol and so-called hard drugs (cocaine and heroin) are said to make communication with potential clients easier (Degraaf et al., 1995; Logan, Leukefeld, \& Farabee, 1998; Maher, 1997). Some drug using SW also use drugs in order to increase their sexual performance and enjoyment. Other SW consider drug use as a strategy to avoid sex. They try to control the situation by using fewer drugs themselves, and having the client use more (Falcón, 2007; Needle et al., 2008; Shannon et al., 2008).

Many international studies have been dedicated to drug use among SW. However, their findings, particularly prevalence data regarding drug use, are hard to compare. This is due to differences in target populations (the different sectors of the sex industry), variations in definitions of the target population and inclusion criteria, variations in the drugs studied, different recruitment and data collection strategies and the complex impact of the local economic, cultural and political context of both sex work and drug use.

Nevertheless, most studies indicate that the prevalence of substance use in general and illegal drug use in particular is higher among SW than among the general population (Haasen, 2001; Gossop et al., 1994). This finding does not only hold true for illegal drug use but also for alcohol use. Countless studies have shown higher lifetime prevalence (once in a lifetime use), higher prevalence of weekly or daily alcohol use, and higher quantities or doses per user among SW (Folch et al., 2008; Gossop et al., 1995; Inciardi, Surratt, Kurtz, \& Weaver, 2005; Li, Li, \& Stanton, 2010; Plant, Plant, \& Thomas, 1990; Potterat, Rothenberg, Muth, Darrow, \& Phillips-Plummer, 1998). Moreover, it is known that drug using SW often use more than one product (Brecht, Huang, Evans, \& Hser, 2008; Falcón, 2007; Lorvick, Martinez, Gee, \& Kral, 2006; Surratt, Inciardi, \& Kurtz, 2006). In addition, the type of sex work seems to have a strong impact on patterns of drug use among SW. Alcohol use takes on larger proportions in bars and clubs (Degraaf et al., 1995). It is assumed that street SW use more drugs and more frequently, that they inject drugs more often, that their use is more problematic and that they appear to be more dependent than SW who work at other locations (Gilchrist, Gruer, \& Atkinson, 2005;
Harcourt, van Beek, Heslop, McMahon, \& Donovan, 2001).

Apart from the work-related health risks and the higher risk of drug use with which they are confronted, SW have less access to health services. Often, they do not speak the local language, they do not know what support services are available, they may not be motivated or lack papers and above all, they are afraid of disapproval and incomprehension on the part of professional social and healthcare workers. A number of characteristics of existing treatment services form barriers: programmes lack gender sensitivity, some social or healthcare workers seem unaware of the problems and needs SW face, or their workload exceeds their limits (Kurtz, Surratt, Kiley, \& Inciardi, 2005). Additionally, fear of law enforcement agencies and stigmatization and discrimination by other clients play a role (Jeal \& Salisbury, 2004; Romans, Potter, Martin, \& Herbison, 2001). The stigma associated with drug use hinders access to treatment services; this is in turn reinforced by the stigma carried by sex work (Smith \& Marshall, 2007). Research shows that SW who use drugs often neglect their health and only seek help when their symptoms reach an advanced stage; healthcare is not a priority (Carr et al., 1996).

Data regarding drug use among SW in Belgium are virtually non-existent. A large-scale study was set up in 2009 and 2010 aiming to describe the nature and extent of legal and illegal drug use among female SW in Belgium. Respondents were recruited in five different sectors of the sex industry: window sex work, street sex work, bar and club sex work, the private sector and the escort sector. The effects of drug use on sex work were studied and the use of healthcare and the drug-related needs of SW were mapped and reported in a Belgian national report (Decorte, Stoffels, Leuridan, Van Damme, \& Van Hal, 2011).

This paper focuses on a part of this large-scale study, namely on SW in bars and clubs. In these bars or clubs, alcohol is served and services are performed in a separate room. Bar prostitution can also be combined with window prostitution: women advertise themselves behind a window, which connects to a bar. The focus on bar and club prostitution is chosen because in this sector, alcohol consumption is an integral part of the work routine: sex workers often receive part of the consumption returns. The major part of the income of the SW is not based on the sexual services they provide, but rather on the amount of alcohol they consume with clients. The specific focus was also chosen because most studies focus on street sex work (Cusick, 2006) and less on bar and club sex work, as this is a less visible and less accessible sector.

\section{METHODS}

The study was based on the principle of informed consent. Moreover, the anonymity of all respondents was guaranteed at any given time. The research project 
was presented and approved by the Ethical Review Board of the Faculty of Law at Ghent University and the Belgian Commission for the Protection of Privacy.

A cross-sectional study was carried out using a multi-method design. In a quantitative component, 120 bar and club SW were interviewed face-to-face by means of a semi-structured questionnaire, which included questions on their patterns of legal and illegal drug use, their drug-related health problems and needs (if any), and their experiences with treatment services. The participants in this survey were recruited through privileged access interviewers (PAIs) in and around five different Belgian cities (Ghent, Antwerp, Brussels, Charleroi and Liège). The PAIs were professionally connected to the target population: they worked as employees or trainees for Belgian non-governmental organizations (NGO) that provide free and anonymous preventive and curative healthcare to SW (NGO Ghapro, NGO Pasop and NGO Espace P). These professional organisations offer free and anonymous support to both female and male SW for work-related problems. They offer information on STIs, contraception, lubricants and safe sex, provide medical examinations (testing for hepatitis B, HIV, syphilis, gonorrhoea, chlamydia) and medical treatment as well as legal, administrative and psychological support. These organisations provide open consultation hours and also work with outreach teams of doctors and nurses who pay daily visits to the workplaces of SW (especially all visible places such as windows, bars and clubs). In addition, they proactively screen newspapers and the internet for SW advertising their services, and contact them to offer their support. These organisations reach hundreds of new clients every year, but it is clear that a sizeable number of SW remain hidden, even to these organisations.

The interviewers were trained intensively by the research team to collect data. Contact was made easier by the existing connection between the PAIs and the target population; they already had established trusting relationships with the target population, and knew many of the participants in the study. The PAIs were required to sign a pledge of ethical behaviour and were informed of the consequences of falsification and unintentional errors of measurement. The pledge outlined the importance of data integrity. Every incoming questionnaire was reviewed by the research team; those containing highly inconsistent answers were removed from the database. Including local program staff as interviewers gave an opportunity to speak with women in-depth; an asset compared to a scientific researcher in the field. As a researcher, it is often not possible to create a relationship of trust with a respondent.

In a first qualitative component, $25 \mathrm{SW}$ were interviewed face-to-face by means of a topic list. These qualitative interviews focused on the life stories and perspectives of female SW. After participating in the questionnaire, the SW were asked whether they were interested in taking part in an interview. In order to take part, SW had to have used drugs or be drug users at the time of the interview. Experience with drug treatment services was not a prerequisite for eligibility.

A second qualitative component consisted of five focus group discussions with key actors who were professionally involved with the study subject. These key actors included representatives of prostitution organisations, social work organisations, ambulant and residential drug treatment centres and of the local and federal police. Together, participants discussed and interpreted the findings obtained from the questionnaires and interviews with the SW. They reflected upon possible and suitable methods and strategies to meet the drug-related health problems and needs faced by SW (if any).

For the use of alcohol, benzodiazepines, cannabis, cocaine, amphetamines, crack, heroin and ecstasy data on lifetime and last month prevalence is described. The dependence on drugs is examined according to the Severity of Dependence Scale (SDS). The SDS evaluates the participant's psychological dependence on certain intoxicants by means of items about the individual's concern or anxiety about the use or the feeling of losing control over the use (Gossop, Marsden, \& Stewart, 2002). Also the combined and poly drug use is assessed. Further, we look at the dysfunctional and functional effects of drug use on sex work and the role of the owners or managers of bars and clubs. Finally, the use of healthcare and the drugrelated needs of SW is discussed. The results shown below are derived from the quantitative part of the study, unless otherwise stated.

\section{RESULTS}

\section{Characteristics of the respondents}

The 120 questioned bar and club sex workers were all female, except for one transgender. The mean age is 32.2 years. Age categories can be found in Table I, as well as the educational level and marital status. The average number of children is 1.8. On average, respondents were 24.6 years old when they started sex work and they have on average 7.7 years experience as a sex worker.

\section{Lifetime and last month prevalence of drugs}

Nearly all respondents used alcohol at least once in their life (96.7\%) (Table II). From the qualitative interviews, it appears that the fact that there are women who have never consumed alcohol in their life, is related to the Islamic background of some respondents: 'My religion does not allow me to drink'. Of those SW who consumed alcohol during the month prior to the questionnaire, almost half (46.2\%) used alcohol at least four times a week and $58.3 \%$ of these current alcohol users consumed six or more units of alcohol on one occasion (heavy drinking). Just over two-thirds 
Table I. Characteristics of the SW (\%).

\begin{tabular}{|c|c|}
\hline \multicolumn{2}{|l|}{ Age } \\
\hline $18-24$ years & 18.5 \\
\hline 25-34 years & 47.1 \\
\hline $35-44$ years & 26.1 \\
\hline$\geq 45$ years & 8.3 \\
\hline \multicolumn{2}{|l|}{ Educational level } \\
\hline Primary education & 9.3 \\
\hline Secondary education & 67.6 \\
\hline Higher education & 23.1 \\
\hline \multicolumn{2}{|l|}{ Marital status } \\
\hline Single & 56.3 \\
\hline Divorced, not remarried & 12.6 \\
\hline Married & 12.6 \\
\hline Cohabiting with partner & 18.5 \\
\hline
\end{tabular}

Table II. Lifetime and last month drug prevalence and drug dependence according to the SDS (\%).

\begin{tabular}{lccc}
\hline & $\begin{array}{c}\text { Lifetime } \\
\text { prevalence } \\
\text { of all } \\
\text { respondents }\end{array}$ & $\begin{array}{c}\text { Last month } \\
\text { prevalence } \\
\text { of all } \\
\text { respondents }\end{array}$ & $\begin{array}{c}\text { Dependence } \\
\text { of the product } \\
\text { among } \\
\text { current users }\end{array}$ \\
\hline Alcohol & 96.7 & 88.4 & 25.5 \\
Benzodiazepines & - & 19.2 & 56.5 \\
Cannabis & 60.0 & 20.8 & 28.0 \\
Cocaine & 46.7 & 18.3 & 36.4 \\
Amphetamines & 25.0 & 2.5 & 0 \\
Crack & 2.5 & 1.7 & 100 \\
Heroin & 9.2 & 0.8 & 100 \\
Ecstasy & 38.3 & 0 & 0 \\
\hline
\end{tabular}

$(67.2 \%)$ of the heavy drinkers did this at least twice a week. $15.1 \%$ of the current alcohol users drink alcohol daily. Alcohol was mostly consumed on working days: on a day off, women consumed on average 0.9 units of alcohol; on a working day this increased to 6.6 units. The qualitative part shows that some respondents are obliged to drink alcohol at work, as this is their main source of income. A lot of SW preferred earning money by consuming alcohol with clients to earning money through sexual services. They try to avoid sexual contact as much as possible. Other SW only offer sexual services and do not earn money through shared alcohol consumption.

Benzodiazepines include tranquillizers such as lorazepam (Temesta $\odot$ ), diazepam (Valium $\odot$ ) and flunitrazepam (Rohypnol( ). About one in five respondents $(19.2 \%)$ had used benzodiazepines during the month prior to the questionnaire. As in most general population surveys, a question related to lifetime prevalence of benzodiazepine use was not included in our questionnaire (Decorte, Mortelmans, Tieberghien, \& De Moor, 2009). This type of medication is mostly used on prescription. Of all benzodiazepines users, $8.7 \%$ bought their substances in the black market. During focus group discussions, it was indicated that
Table III. Lifetime (LTP) and last month drug prevalence (LMP) among other sex work sectors (\%).

\begin{tabular}{lcccc}
\hline & Street & Window & Private & Escort \\
\hline Alcohol & & & & \\
LTP & 96.3 & 89.3 & 98.6 & 92.5 \\
LMP & 68.2 & 55.7 & 81.3 & 82.5 \\
Benzodiazepines & & & & \\
LTP & - & - & - & - \\
LMP & 35.5 & 23.0 & 26.6 & 27.5 \\
Cannabis & & & & \\
LTP & 72.0 & 36.1 & 68.3 & 52.5 \\
LMP & 36.4 & 18.0 & 28.8 & 12.5 \\
Cocaine & & & & \\
LTP & 62.6 & 26.2 & 46.0 & 47.5 \\
LMP & 28.0 & 9.8 & 15.1 & 7.5 \\
Amphetamines & & & & \\
LTP & 32.7 & 15.6 & 30.2 & 37.5 \\
LMP & 3.7 & 1.6 & 5.0 & 10.0 \\
Crack & & & & \\
LTP & 22.4 & 2.5 & 7.2 & 5.0 \\
LMP & 11.2 & 0.8 & 1.4 & 2.5 \\
Heroin & & & & \\
LTP & 46.7 & 3.3 & 8.6 & 12.5 \\
LMP & 33.6 & 0 & 0.7 & 0 \\
Ecstasy & & & & \\
LTP & 31.8 & 15.6 & 41.7 & 47.5 \\
LMP & 0 & 0.8 & 2.9 & 10.0 \\
\hline
\end{tabular}

these findings on use run parallel with the trends found among the general population. On the one hand, benzodiazepine use is often connected with psychological problems and, on the other, with the (unnecessary or exaggerated) prescription behaviour of doctors. Among the current benzodiazepine users, $60.9 \%$ used these substances daily.

Over half of respondents $(60.0 \%)$ had used cannabis at least once. It was the most commonly used illegal substance among respondents. Roughly one-fifth of all respondents $(20.8 \%)$ had used cannabis during the 30 days prior to the questionnaire. Over half of the current users $(56.0 \%)$ claimed to use cannabis on a daily basis. The qualitative interviews showed that cannabis is often used in order to relax after a day at work.

Of all respondents, less than half $(46.7 \%)$ had ever used cocaine. About one-fifth of all respondents (18.3\%) had used cocaine during the month prior to the questionnaire and $59.1 \%$ of the current users did this at least once a week. Almost three quarters of the current users $(72.7 \%)$ used cocaine at work.

No respondents had used ecstasy during the month preceding the questionnaire, three respondents had used amphetamines (speed), two respondents crack and one respondent heroin.

To frame the results of the lifetime and last month prevalence of drugs among bar and club SW, data are compared with those of SW from the other sex work sectors questioned in this study (Table III): street sex 
work $(N=106)$, window sex work $(N=122)$, the private sector $(N=137)$, and the escort sector $(N=40)$.

\section{Severity of dependence scale}

The last column of Table II shows the respondents' psychological dependence for all products among the current users (the respondents who used the product during the month preceding the questionnaire). In total, about one-fourth $(25.5 \%)$ of the current users are dependent on alcohol, according to the SDS. Of the current benzodiazepines users, $56.5 \%$ are dependent on the product. For the current cannabis and cocaine users, $28.0 \%$ and $36.4 \%$, respectively, are dependent on the product. In all, $35.0 \%$ of the total sample was dependent on at least one product.

\section{Poly drug use and combined drug use}

Of the 120 bar and club SW, $90.8 \%$ used at least one type of drug during the month prior to the questionnaire. About half of them (48.6\%) had used multiple substances in the last month (poly drug use). When examining the combined use (i.e., using multiple products at the same time), we note that approximately one in three $(30.3 \%)$ of current users did this in the last month. The most frequent combinations were alcohol and cocaine $(42.4 \%)$, followed by alcohol and cannabis $(30.3 \%)$. Several participants in the focus group discussions and the qualitative interviews mentioned the combination of alcohol with cocaine. SW who earn part of their wage by consuming alcohol perceive alcohol consumption as a part of their job. Alcohol and cocaine are used together or alternately in order to work long shifts or to feel less drunk: 'Without coke it is not sustainable. When you sniff a line, you feel better and you can continue drinking'. In the bar and club sector, cocaine use and alcohol consumption often go hand in hand. In addition, a number of participants from the focus group discussions thought that this combination was often used as an antidepressant.

\section{The sex workers' perspective: Functional and dysfunctional use}

In the quantitative part, the respondents were asked whether their drug use effects the sex work. Both dysfunctional and functional effects were given (Table IV).

The dysfunctional effects of drug use on sex work are mainly manifested in the working hours and the number of clients SW can receive. Almost half of the respondents indicated that they can work less long and about one-third can receive fewer customers when they are under the influence. Some were less selective when choosing clients or had already had unprotected sex due to the use of drugs.

Looking at the functional effects of drug use on sex work, we can see that of all respondents, more than half indicated the sex work was easier for them when they were under the influence of drugs. Approximately onethird was more self-assured during the negotiations
Table IV. Effects of drug use on sex work (\%).

\begin{tabular}{|c|c|c|c|}
\hline \multirow{2}{*}{$\frac{\text { Dysfunctional effects }}{\text { Can work less long }}$} & \multicolumn{3}{|c|}{ Functional effects } \\
\hline & 46.5 & Can work longer & 34.3 \\
\hline $\begin{array}{l}\text { Can receive fewer } \\
\text { customers }\end{array}$ & 31.3 & $\begin{array}{l}\text { Can receive } \\
\text { more customers }\end{array}$ & 28.3 \\
\hline $\begin{array}{l}\text { Less selective } \\
\text { in clients }\end{array}$ & 21.2 & Improved negotiation & 36.7 \\
\hline Unprotected sex & 12.2 & Easier to reject clients & 29.6 \\
\hline & & Makes sex work easier & 56.1 \\
\hline
\end{tabular}

with the clients about sex techniques and the price that would be charged for them. About one-third indicated they could work longer and that they could reject clients more easily. More than one-fourth felt capable of receiving more customers due to the use of drugs.

\section{The role of the managers and clients}

The qualitative part of the study showed that the establishment's infrastructure and the managers or owners play an important factor in the prevalence of substance use or abuse at the workplace. There are major differences between bars. A typical phenomenon in this sector is the 'dame de compagnie' or 'ladycompanion'. Some 'dames de compagnie' safeguard the well being of the SW, while others only have a control function. A lot also depends on whether the 'dame de compagnie' or manager uses her- or himself and whether she or he tolerates use in others. Some establishments allow SW to pour away champagne when the client is not looking, other bars do not: 'At my previous club you had to drink everything. You couldn't pour away even a drop. There, every night was a disaster. But here your flip-flops stick to the carpet, because of all the alcohol we pour away'. Some managers encourage use or even force employees to use drugs, others show zero tolerance towards illegal drug use at work. It also happens that managers supply the drugs to the SW: 'The boss was always present and we bought from him. We all placed our order with him'.

Drug use among SW can also be linked to drug use among clients. The qualitative interviews show that some clients bring drugs along with them; others actively look for SW who provide drugs to use while having sex. When no drugs is allowed, some go somewhere else. Some clients arrive under the influence, others want to use at the scene. As such, clients can play an important role in the supply of drugs. The quantitative part of our study shows that of all respondents, $15.8 \%$ use illegal drugs together with clients. Mostly, it concerns cocaine: $15.0 \%$ of all respondents occasionally or often use cocaine together with clients.

The use of healthcare and drug-related needs of SW The number of respondents who had ever had contact with a professional social or healthcare worker 
regarding their drug use was $13.9 \%$. Of those who are characterized on the basis of the SDS as dependent on at least one product, $23.8 \%(n=10 / 42)$ had already consulted a professional social or healthcare worker.

The qualitative part of the study showed that drugrelated problems are often not addressed because they are minimized or denied, or they are considered as transient or as a non-priority: 'As long as you keep functioning, it is not so bad'. Some even apply their own strategies to regulate or temper their substance use: 'I had enough because my teeth became all black, so I stopped smoking cocaine because of the side effects and started to sniff'.

The difficulties SW face before approaching drugrelated healthcare, are due to a variety of factors, as cited in the qualitative part of the study. Many of the SW are scared of not being taken seriously by the police and other authorities. The respondents mostly emphasized the negative prejudices towards their work, the lack of regulation and the taboo surrounding the profession and the resulting social consequences: the double life, the loneliness and the social isolation. In addition, SW often do not know what healthcare assistance is available and they do not find it so easy to seek drug-related help. There is a need for more information for SW about the risks of substance use, the possible negative impact on the sex work and other areas of life, and the healthcare assistance available for drug-related problems.

Other problems that appear from the qualitative part are the shortage of facilities or resources to meet the demand (long waiting lists), the geographical location of healthcare facilities (too far or in a 'rough' area), the lack of specialized services and centres, the range of existing prostitution organizations, the lack of care tailored to the individual person, the need for counselling during the process, career counselling and aftercare (with a focus on exit strategies from the sex world), the need for additional harm reduction actions, and cultural and language barriers within the (drug) healthcare. Care providers do not always know how they should deal with SW and drug users as a target group.

\section{DISCUSSION}

This study focuses by definition on a hidden and hard to reach population. Both sex work and drug use entail a social taboo and stigmatisation. As the study objective becomes more sensitive and more threatening, the likelihood that respondents will deny their involvement increases. This probably leads to an underreporting of drug use by SW. The fact that we recruited our participants through privileged access interviewers (professionally connected to the target population), and the fact that many respondents admitted their drug use, may suggest that this underreporting is limited in our study.
The size of the SW population in Belgium as a whole is not known. Official figures are sparse and often only represent estimations of the number of people that perform sex work. The drawing of a representative sample from a population that is unknown, is practically impossible. In addition, the respondents were recruited through professional organisations for $\mathrm{SW}$, which could have led to a certain distortion of the results. After all, it concerns SW who have built up a good relationship of trust with these organisations. An attempt has, however, been made to compile a sufficiently varied sample which takes the possible geographical variations into account. It therefore has to be kept in mind that the results are probably not representative for the group of sex workers as a whole nor for those working in Belgian bar and club sex work, but the results may still be indicative of important links between sex work and drug use.

If we want to reduce drug use and its related damage, it is important to understand what role legal and illegal drugs play and to what extent they affect the life of the target group. Of the respondents working in the bar and club sector, nearly $90 \%$ reported alcohol consumption during the last month. Many SW active in this sector drink frequently and engage in heavy drinking. Alcohol consumption seems to be part of the job and drinking alcohol with clients is often a more important source of income than the income received from sexual services. Measures to reduce drug use and its related damage in this sex work sector should take these characteristics into account, but this is clearly not easy.

Not only alcohol, but also illegal drugs are frequently used by the respondents. Cannabis use during the past month was reported by more than a fifth of the respondents. Nearly a fifth indicated the use of cocaine and benzodiazepines during the past month.

Often the drug use involves poly drug use or combined drug use. The most common combinations are alcohol and cocaine, and alcohol and cannabis. The combined use of alcohol and cocaine seems to be a strategy to cope with and to continue the profession as a SW. These findings are consistent with findings in other international research (Brecht et al., 2008; Falcón, 2007; Lorvick et al., 2006; Surratt et al., 2006).

The respondents were asked to what extent they experienced a (positive or negative) influence of drug use on sex work. The use of drugs seems to be inseparably linked to sex work for some respondents. A complex relation, however, exists between drug use and sex work. Some respondents claim to use in order to be able to work longer, while others can work less long when under influence. Also, some SW are able to receive more clients under influence of drugs, while others receive less.

The qualitative data also suggest that managers play an important role in the occurrence, availability and tolerance of substance use in the workplace. Much 
depends on whether the manager uses him- or herself and whether he or she tolerates use in others. Some managers even encourage the use of drugs. Also the clients have an important role in the drug use among SW. It is alarming that $15.0 \%$ of all respondents occasionally or often use cocaine together with clients.

Comparing prevalence data from this study against data regarding the general Belgian population is particularly difficult. Contrary to most European member states, Belgium has no tradition of general population surveys on drug use. The Belgian national Health Interview Survey (HIS) offers some comparable data, although important differences are found in age. The age in the HIS ranges between 15 to 64 years, as compared to 19 to 55 years in this study. According to the HIS, $8.7 \%$ of the general female population drinks alcohol daily (Gisle et al., 2010) compared to $15.1 \%$ in this study. According to the most recent HIS, $1.9 \%$ of the female Belgian population (aged 15 or older) used cannabis during the last month prior to the interview (Gisle et al., 2010). Last month's cannabis prevalence among the sample in this study is more than ten times higher: $20.8 \%$. Data regarding cocaine also suggest differences in prevalence patterns: according to the HIS, $0.5 \%$ of Belgian women report use of cocaine during the last twelve months (Gisle et al., 2010). In this study, $18.3 \%$ of the SW report cocaine use in the month prior to the interview. Our findings suggest that drug use among this particular group is more common than among the general population.

As mentioned in the introduction, an international comparison of prevalence data regarding drug use among SW is nearly impossible, as there are significant differences regarding sex work sectors or populations studied, different criteria on inclusion and exclusion, as well as different strategies for recruitment and data collection (some studies for example recruit their participants through HIV prevention programmes) (Roxburgh, Degenhardt, Copeland, \& Larance, 2008; Zurhold, 2005). In addition, studies often focus on local sex work phenomena, which are shaped by contextual factors, such as local drug and prostitution policies, the availability of drugs and other characteristics of local drug markets, as well as general trends of drug use among the local population (Cusick, 2006).

The comparison of the lifetime and last month prevalence of drug use among bar and club SW with prevalence among SW from the current study's wider sample of SW, shows that in particular the use of alcohol among bar and club SW is high compared to this use in other sectors. Of the bar and club SW, $88.4 \%$ consumed alcohol during the month prior to the questionnaire, whereas in the other sectors this was lower (street: $68.2 \%$; window: $55.7 \%$; private: $81.3 \%$ and escort: $82.5 \%$ ). The lifetime and last month prevalence of cannabis among bar and club SW is average compared to the use in the other sectors, and the last month use of cocaine is only higher in the group of street SW. The last month prevalence of benzodiazepines, however, was the lowest in the group of bar and club SW compared to the SW from the other sectors.

By means of the SDS, we examined whether the reported use could be regarded as problematic. More than one-third of the respondents experienced a certain degree of dependence on one or more legal or illegal drugs. It should be noted that SW who are dependent on a product according the SDS, are not necessarily experiencing problems. They might not see their substance use as 'problematic'. With these numbers, derived from a cross-sectional study, it cannot be determined whether there is a causal relationship between the sex work and any dependency problems. Many authors, however, believe that the social characteristics of sex work create a context of drug use. These factors include both individual characteristics of the SW (knowledge, attitudes and competences) and complex interactions between environmental, individual, relational, situational and institutional influences (Li et al., 2010).

The prevalence of drug use among bar and club SW and the influence of drug use on sex work illustrates the need for drug and sex work related healthcare. Of all respondents, about one-tenth had ever looked for professional drug treatment. Of those who were dependent according to the SDS, only one in four had ever had contact with a professional social or healthcare worker regarding their drug use.

Again, comparison with general population is difficult, since there exist no similar national data regarding drug dependence. According to the HIS, $0.6 \%$ of the female Belgian population aged 15 to 64 years, took several different drugs in the past twelve months (Gisle et al., 2010). In 2010, a total of 8505 persons were registered for demanding professional drug treatment. Of this 8505 persons, $18.0 \%$ was female (Deprez et al., 2011).

Our study shows that SW often have difficulty reaching drug-related healthcare. This may be due to multiple factors, including the lack of regulation and the taboo surrounding the profession of sex worker, as also evidenced in other research (Jeal \& Salisbury, 2004; Kurtz et al., 2005; Romans et al., 2001).

Therefore, one recommendation based on the present results would be the distribution of more information about the risks of drug use, the possible negative effect on sex work and other areas of life, and the available drug-related healthcare. Not only SW themselves should be involved, but also other actors such as the managers who, because of their position of authority, could play a role in the oral or written dissemination of useful information. A campaign aiming at the clients of SW could also play a positive role. More research is needed to determine the best possible formats to disseminate information appropriate to the particular conditions of bar and club sex work. 


\section{ACKNOWLEDGEMENTS}

The authors would like to acknowledge Ilona Stoffels, who assisted with the development of the instrument, data collection and write-up of the research report for Belgian Science Policy. The authors would like to thank the staff at Pasop (Ghent), Ghapro (Antwerp) and Espace P (Brussels, Charleroi and Liège) for their cooperation in facilitating access to their clients and their contribution to field interviews. Finally, we are indebted to the 528 women interviewed for this project, which generously gave their time and spoke openly about their involvement in the sex industry and in drug use. We would like to express our thanks to the Federal Science Policy BELSPO as principal subsidizer of the study.

Declaration of interest: The authors report no conflicts of interest. The authors alone are responsible for the content and writing of the article.

This manuscript is based on research funded by the Belgian Science Office (DRUSEB - DR/38).

\section{REFERENCES}

Brecht, M.L., Huang, D., Evans, E., \& Hser, Y.I. (2008). Polydrug use and implications for longitudinal research: Tenyear trajectories for heroin, cocaine, and methamphetamine users. Drug and Alcohol Dependence, 96, 193-201.

$\checkmark$ Brooke, D., Taylor, C., Gunn, J., \& Maden, A. (1998). Substance misusers remanded to prison - a treatment opportunity? Addiction, 93, 1851-1856.

-Carr, S., Goldberg, D.J., Elliott, L., Green, S., Mackie, C., \& Gruer, L. (1996). A primary health care service for Glasgow street sex workers - 6 years experience of the 'Drop-in Centre', 1989-1994. Aids Care, 8, 489-497.

Cusick, L. (2006). Widening the harm reduction agenda: From drug use to sex work. International Journal of Drug Policy, 17, 3-11.

Day, S., \& Ward, H. (1997). Sex workers and the control of sexually transmitted disease. Genitourinary Medicine, 73, 161-168.

Decorte, T., Mortelmans, D., Tieberghien, J., \& De Moor, S. (2009). Feasibility study of a repetitive prevalence study among the general population. Ghent: Academia Press (in Dutch).

Decorte, T., Stoffels, I., Leuridan, E., Van Damme, P., \& Van Hal, G. (2011). Substance use among sex workers in Belgium. Ghent: Academia Press (in Dutch).

Degraaf, R., Vanwesenbeeck, I., Vanzessen, G., Straver, C.J., \& Visser, J.H. (1995). Alcohol and drug-use in heterosexual and homosexual prostitution, and its relation to protection behavior. Aids Care, 7, 35-47.

Deprez, N., Antoine, J., Asueta-Lorente, J.F., Bollaerts, K., Van der Linden, T., \& van Bussel, J. (2011). 2011 National Report (2010 data) to the European Monitoring Centre for Drugs and Drug Addiction. Brussels: Scientific Institute of Public Health.

Falcón, C.M. (2007). Consequences of cocaine use among prostitutes. Gaceta Sanitaria, 21, 191-196.

-Folch, C., Esteve, A., Sanclemente, C., Martró, E., Lugo, R., Molinos, S., ... Casabona, J. (2008). Prevalence of human immunodeficiency virus, Chlamydia trachomatis, and Neisseria gonorrhoeae and risk factors for sexually transmitted infections among immigrant female sex workers in Catalonia, Spain. Sexually Transmitted Diseases, 35, 178-183.

-Gilchrist, G., Gruer, L., \& Atkinson, J. (2005). Comparison of drug use and psychiatric morbidity between prostitute and non-prostitute female drug users in Glasgow, Scotland. Addictive Behaviors, 30, 1019-1023.

Gisle, L., Hesse, E., Drieskens, S., Demarest, S., Van der Heyden, J., \& Tafforeau, J. (2010). Health Interview Survey, Belgium, 2008. Report $n r . \quad 2$ : Lifestyle and prevention. Brussels: Scientific Institute of Public Health (in Dutch).

Gossop, M., Powis, B., Griffiths, P., \& Strang, J. (1994). Sexualbehavior and its relationship to drug-taking among prostitutes in South London. Addiction, 89, 961-970.

- Gossop, M., Powis, B., Griffiths, P., \& Strang, J. (1995). Female prostitutes in South London - Use of heroin, cocaine and alcohol, and their relationship to health risk behaviors. Aids Care, 7, 253-260.

$\checkmark$ Gossop, M., Marsden, J., \& Stewart, D. (2002). Dual dependence: Assessment of dependence upon alcohol and illicit drugs, and the relationship of alcohol dependence among drug misusers to patterns of drinking, illicit drug use and health problems. Addiction, 97, 169-178.

Haasen, C. (2001). Patterns of consumption. European Addiction Research, 7(1), 1.

-Harcourt, C., van Beek, I., Heslop, J., McMahon, M., \& Donovan, B. (2001). The health and welfare needs of female and transgender street sex workers in New South Wales. Australian and New Zealand Journal of Public Health, 25, 84-89.

Inciardi, J.A., Surratt, H.L., Kurtz, S.P., \& Weaver, J.C. (2005). The effect of serostatus on HIV risk behaviour change among women sex workers in Miami, Florida. AIDS Care, 17, S88-S101.

$\checkmark$ Jeal, N., \& Salisbury, C. (2004). Self-reported experiences of health services among female street-based prostitutes: A cross-sectional survey. British Journal of General Practice, $54,515-519$.

Kumar, M.S., \& Sharma, M. (2008). Women and substance use in India and Bangladesh. Substance Use \& Misuse, 43, 1062-1077.

Kurtz, S.P., Surratt, H.L., Kiley, M.C., \& Inciardi, J.A. (2005). Barriers to health and social services for street-based sex workers. Journal of Health Care for the Poor and Underserved, 16, 345-361.

Li, Q., Li, X., \& Stanton, B. (2010). Alcohol use among female sex workers and male clients: An integrative review of global literature. Alcohol and Alcoholism, 45, 188-199.

$\checkmark$ Logan, T.K., Leukefeld, C., \& Farabee, D. (1998). Sexual and drug use behaviors among women crack users: Implications for prevention. Aids Education and Prevention, 10, 327-340.

Lorvick, J., Martinez, A., Gee, L., \& Kral, A.H. (2006). Sexual and injection risk among women who inject methamphetamine in San Francisco. Journal of Urban Health, 83, 497-505.

Maher, L. (1997). Sexed work: Gender, race and resistance in a Brooklyn drug market. Oxford: Clarendon Press.

-Mak, R., Van Renterghem, L., \& Cuvelier, C. (2004). Cervical smears and human papillomavirus typing in sex workers. Sexually Transmitted Infections, 80, 118-120.

Maxwell, S.R., \& Maxwell, C.D. (2000). Examining the "criminal careers" of prostitutes within the nexus of drug 
use, drug selling, and other illicit activities. Criminology, 38, 787-810.

Needle, R., Kroeger, K., Belani, H., Achrekar, A., Parry, C.D., \& Dewing, S. (2008). Sex, drugs, and HIV: Rapid assessment of HIV risk behaviors among street-based drug using sex workers in Durban, South Africa. Social Science \& Medicine, 67, 1447-1455.

Plant, M.L., Plant, M.A., \& Thomas, R.M. (1990). Alcohol, AIDS risks and commercial sex: Some preliminary results from a Scottish study. Drug and Alcohol Dependence, 25, 51-55.

Potterat, J.J., Rothenberg, R.B., Muth, S.Q., Darrow, W.W., \& Phillips-Plummer, L. (1998). Pathways to prostitution: The chronology of sexual and drug abuse milestones. Journal of Sex Research, 35, 333-340.

Romans, S.E., Potter, K., Martin, J., \& Herbison, P. (2001). The mental and physical health of female sex workers: A comparative study. Australian and New Zealand Journal of Psychiatry, 35, 75-80.

-Roxburgh, A., Degenhardt, L., Copeland, J., \& Larance, B. (2008). Drug dependence and associated risks among female street-based sex workers in the greater Sydney area, Australia. Substance Use \& Misuse, 43, 1202-1217.
Shannon, K., Kerr, T., Bright, V., Gibson, K., \& Tyndall, M.W. (2008). Drug sharing with clients as a risk marker for increased violence and sexual and drugrelated harms among survival sex workers. Aids Care, 20, 235-241.

-Smith, F.M., \& Marshall, L.A. (2007). Barriers to effective drug addiction treatment for women involved in street-level prostitution: A qualitative investigation. Criminal Behaviour and Mental Health, 17, 163-170.

Surratt, H.L., Inciardi, J.A., \& Kurtz, S.P. (2006). Prescription opioid abuse among drug-involved street-based sex workers. Journal of Opioid Management, 2, 283-289.

-Ward, H., \& Day, S. (2006). What happens to women who sell sex? Report of a unique occupational cohort. Sexually Transmitted Infections, 82, 413-417.

-Young, A.M., Boyd, C., \& Hubbell, A. (2000). Prostitution, drug use, and coping with psychological distress. Journal of Drug Issues, 30, 789-800.

Zurhold, H. (2005). Developmental pathways of girls and young women in drug-related prostitution. Berlin: VWN Verlag (in German). 